FRBSF Working Paper 2002-02

\title{
Assessing the Lucas Critique in Monetary Policy Models
}

\author{
Glenn D. Rudebusch* \\ Federal Reserve Bank of San Francisco \\ June 2002 \\ first draft, February 2002
}

\begin{abstract}
Empirical estimates of monetary policy rules suggest that the behavior of U.S. monetary policymakers changed during the past few decades. However, at the same time, statistical analyses of lagged representations of the economy, such as VARs, often have not rejected the null of structural stability. These two sets of empirical results appear to contradict the Lucas critique. This paper provides a reconciliation by showing that the apparent policy invariance of reduced forms is consistent with the magnitude of historical policy shifts and the relative insensitivity of the reduced forms of plausible forward-looking macroeconomic specifications to policy shifts.

JEL classification: E17, E52
\end{abstract}

\footnotetext{
${ }^{*}$ Homepage: www.frbsf.org/economists/grudebusch; email: Glenn.Rudebusch@sf.frb.org; address: 101 Market Street, San Francisco, CA, 94105. For helpful comments, I thank many colleagues in the Federal Reserve System as well as Adrian Pagan, Tom Sargent, Carl Walsh, and participants in seminars at Berkeley and the University of Hawaii. Kirran Bari and Adam Yu provided excellent research assistance. The views expressed in this paper do not necessarily reflect those of the Federal Reserve System.
} 


\section{Introduction}

Lucas (1976) argued that the parameters of traditional macroeconometric models depended implicitly on agents' expectations of the policy process and were unlikely to remain stable as policymakers changed their behavior. This critique was influential in two respects. First, it helped re-orient macroeconomic research toward models with explicit expectations and "deep" parameters of taste and technology. These models, which were to be invariant to policy shifts, included estimated first-order conditions or Euler equations, calibrated general equilibrium models with explicit optimization, and, most recently, "New Keynesian" models. Second, the Lucas critique helped change the focus of policy evaluation from consideration of alternative paths of the policy instrument to consideration of alternative policy rules, which allowed individual agents to formulate forward-looking dynamic optimization problems.

The heightened interest in rules has resulted in many recent estimates of the monetary policy rule using postwar U.S. data on a short-term interest rate, output, and inflation. From the standpoint of the Lucas critique, the most interesting result from these studies is that they typically reject the stability of historical monetary policy rules. Notably, Clarida, Gali, and Gertler (2000), Estrella and Fuhrer (2000), Taylor (1999), and Judd and Rudebusch (1998) estimate Taylor rules that exhibit discrete shifts in the response of the Federal Reserve to inflation and output during the past few decades. ${ }^{1}$ This evidence suggests that the Lucas critique should be particularly relevant for monetary policy analysis. Specifically, given the apparent historical policy shifts, the Lucas critique suggests that lagged autoregressive models will be plagued by parameter instability and will make a poor choice for analyzing monetary policy.

In fact, however, empirical autoregressive macroeconomic models without explicit expectations are still widely used for monetary policy analysis. The most prominent examples are the ubiquitous monetary VARs, in which lagged representations of the economy are treated as invariant structural models (e.g., Leeper and Zha, 2001). But researchers have also used other nonexpectational autoregressive macroeconomic models for monetary policy analysis, including Rudebusch and Svensson (1999, 2002), Onatski and Stock (2002), Smets (1999), Dennis (2001), Laubach and Williams (2001), and Fagan, Henry, and Mestre (2001). Even more surprising in view of the Lucas critique is that these VAR and non-VAR macroeconomic models without

\footnotetext{
${ }^{1}$ Rudebusch (1998) also demonstrates the instability of estimated VAR interest rate equations and notes the policy rule instability documented by the earlier reaction function literature.
} 
explicit expectations often appear to be fairly stable empirically. For example, Rudebusch and Svensson (1999), Bernanke and Mihov (1998), Estrella and Fuhrer (2000), Dennis (2001), and Leeper and Zha (2001) all provide evidence of the stability of various autoregressive reduced forms. $^{2}$

These two empirical results - the rejection of stability in estimated monetary policy rules and the inability to reject parameter stability in estimated autoregressive models - appear incompatible with the Lucas critique. This paper tries to provide a reconciliation by assessing the importance of the Lucas critique via a simulation experiment. Specifically, repeated samples of simulated data are drawn from a true data generating process that has forward-looking rational expectations and a policy rule that shifts over time. The applicability of the Lucas critique in this framework is clear, so the parameters of a backward-looking, autoregressive model that is estimated from the simulated data will shift between policy regimes. However, the key issue is the size of the parameter shifts, that is, the importance of the Lucas critique, which can be assessed by examining the economic and statistical significance of changes in the reduced form parameters. $^{3}$

As a first step, Section 2 illustrates the theoretical role of the Lucas critique in monetary policy models by examining changes in the reduced forms of simple calibrated New Keynesian models with alternative Taylor rules for monetary policy. However, the major contribution of this paper is an assessment of the importance of the Lucas critique in an empirical setting. Such a practical assessment of empirical relevance is completely consistent with Lucas (1976). Although the Lucas critique has often been strictly interpreted as a theoretical absolute (i.e., "No policy evaluations without deep parameters!"), with an associated paralyzing effect on the formulation of policy evaluations, in fact, Lucas outlined a clear operational path to create "scientific" evaluations of alternative policies. Such evaluations required careful consideration of the quantitative importance of the expectational effects of alternative policy rules on the economy. As Lucas and Sargent (1981, pp. 302-303) note: "[The] question of whether a particular model is structural is an empirical, not theoretical, one." In this spirit, the analysis below assesses the

\footnotetext{
${ }^{2}$ Some reseachers (e.g., Boivin and Giannoni, 2002) have argued that reduced forms-particularly VARs-do not appear stable in postwar samples. If such instability is in fact widespread, then the analysis below can be motivated as determining how much of the instability in estimated reduced forms reflects the Lucas Critique and shifts in the historical monetary policy rule.

3 An alternative reconciliation would deny the presence of regime shifts in postwar monetary policy. In particular, starting with Sims (1982), some have argued that the examination of discrete, permanent changes in a policy rule is not a realistic case to study. Instead, agents form probability distributions over a range of possible rules, so apparent rule shifts are just draws from a given distribution. This issue is discussed further below.
} 
empirical importance of the Lucas critique in the postwar period.

The methodology used for that assessment is carefully constructed to answer the question: Given historical policy changes and a plausible empirical forward-looking model, will the estimated parameters of an autoregressive model appear unstable in postwar samples? There are three key elements in this framework that are each closely aligned with empirical results in the literature. First, as described in Section 3, an estimated New Keynesian model representing the behavior of forward-looking agents in the economy is the "true" structural model used to generate data. Second, estimated shifts in historical monetary policy rules from the research of Clarida, Gali, and Gertler (2000), Estrella and Fuhrer (2000), and Taylor (1999) are incorporated into the model in Section 4. Third, a popular lagged autoregressive specification is estimated from the data generated by the forward-looking model with a changing policy rule and tested for parameter stability in Section 5. Overall, the autoregressive representation demonstrates a remarkable resiliency to policy rule shifts. This conclusion is robust to variation in the simulation experiment across a number of dimensions - especially in the degree of forward-looking behavior - and it reconciles the postwar empirical results on models and rules with the Lucas critique.

The finding of a modest empirical importance of the Lucas critique echoes Taylor (1989), who applied a similar methodology by simulating an estimated rational expectations model under fixed and flexible exchange rate regimes. In contrast, Lindé (2001) reported significant shifts in reduced forms estimated from synthetic data. However, to generate data, Lindé (2001) used a calibrated business cycle model of the type that does not capture macroeconomic dynamics well (as shown, for example, in Cogley and Nason, 1995) as well as monetary policy rules that are specified in terms of the monetary aggregates, which have an uncertain interpretation during much of the postwar period. In addition, Lindé (2001) examined the stability of very simple consumption and money demand functions that are not of recent empirical interest. The current paper and Taylor (1989), which use estimated models and historical policy rules, are arguably more relevant.

\section{The Lucas Critique in Theoretical Monetary Policy Models}

Lucas (1976) represents the observable reduced form of the economy by

$$
Y_{t+1}=F\left(Y_{t}, X_{t}, \theta, u_{t}\right)
$$


where $Y_{t}$ is a vector of economic variables, $X_{t}$ is a vector of policy instruments, $\theta$ is a parameter vector, and $u_{t}$ represents random shocks. Similarly, a policy rule for setting the policy instrument is given by

$$
X_{t}=G\left(Y_{t}, \lambda, v_{t}\right)
$$

where $\lambda$ is a parameter vector, and $v_{t}$ are random shocks. Lucas (1976) argued that "scientific, quantitative policy evaluation" required comparing alternative policy rules, that is examining changes in $\lambda$, as well as taking into account agents' expectations of future policy actions. He stressed that, "A change in policy (in $\lambda$ ) affects the behavior of the system in two ways: first by altering the time series behavior of $\left[X_{t}\right]$; second by leading to modification of the behavioral parameters $\theta(\lambda)$ governing the rest of the system." The first effect is the obvious direct influence of the change in the policy rule on the dynamics of the system. The second expectational effect captures the fact that changes in the policy rule should alter agents' expectations of the future and, hence, change the reduced-form dynamics of the economy. This sensitivity of the reduced form to the expectational effects of structural policy changes is the essence of the Lucas critique.

This expectational effect can be examined in a small theoretical model of the New Keynesian variety that has become popular in the past few years for monetary policy analysis. ${ }^{4}$ This section examines two versions of this model that are differentiated by the timing of the formation of expectations. The first, more tractable lagged expectational model follows Lansing and Trehan (2001) and has a simple closed-form expression for the reduced form. The other contemporaneous expectational model is a more standard formulation, but one that must be solved numerically. Both versions provide useful insights into the Lucas critique and the empirical results below.

First, consider the lagged expectational model:

$$
\begin{gathered}
y_{t}=\beta_{y}\left[\left(1-\mu_{y}\right) y_{t-1}+\mu_{y} E_{t-1} y_{t}\right]-\beta_{r} r_{t-1}+\eta_{t} \\
r_{t-1}=\left(1-\mu_{r}\right)\left(i_{t-1}-\pi_{t-1}\right)+\mu_{r} E_{t-1}\left(i_{t}-\pi_{t}\right), \\
\pi_{t}=\left(1-\mu_{\pi}\right) \pi_{t-1}+\mu_{\pi} E_{t-1} \pi_{t}+\alpha_{y} y_{t-1}+\varepsilon_{t} .
\end{gathered}
$$

The first equation relates $y_{t}$, the output gap, to $E_{t-1} y_{t}$, the expectation of time $t$ output formed at time $t-1, r_{t}$, the real interest rate, and $\eta_{t}$, a random shock. The second equation defines that real interest rate in terms of the nominal short-term policy rate, $i_{t}$, and the inflation rate,

\footnotetext{
4 Much of the appeal of this model lies in its foundations in a dynamic general equilibrium model with temporary nominal price rigidities. For derivations and discussion, see Walsh (1998), Clarida, Gali, and Gertler (1999), Svensson (1999a, b), and Rudebusch (2001b).
} 
$\pi_{t}$. Finally, inflation is determined by lagged and expected inflation and the output gap along with a stochastic shock $\varepsilon_{t}$. (Constants are omitted throughout.)

This model can capture a wide range of explicit forward-looking behavior through the parameters $\mu_{\pi}, \mu_{y}$, and $\mu_{r}$. At one extreme, the model with $\mu_{\pi}=\mu_{y}=\mu_{r}=0$ matches the completely adaptive expectations model used in Svensson (1997):

$$
\begin{gathered}
y_{t}=\beta_{y} y_{t-1}-\beta_{r}\left(i_{t-1}-\pi_{t-1}\right)+\eta_{t}, \\
\pi_{t}=\pi_{t-1}+\alpha_{y} y_{t-1}+\varepsilon_{t} .
\end{gathered}
$$

At the other extreme, when $\mu_{\pi}=\mu_{y}=\mu_{r}=1$, the equations loosely approximate the loglinearized version of the consumption Euler equation and staggered nominal wage contracting model (though the contemporaneous expectational model discussed below is arguably a closer approximation). As a theoretical matter, the values of the expectational parameters $\mu_{\pi}, \mu_{y}$, and $\mu_{r}$ are not clearly determined. For example, from well-known models of price-setting behavior, it is possible to derive a completely forward-looking expectational inflation equation (see Roberts, 1995). However, many authors assume that with realistic costs of adjustment and overlapping price and wage contracts there will be some inertial lagged inflation influence in price determination (Svensson, 1999a; Fuhrer and Moore, 1995; Fuhrer, 1997; and Christiano, Eichenbaum, and Evans, 2001). Similarly, it is widely agreed that some form of costly adjustment or habit formation must be added to the model in order to match the inertial lagged responses of output that are apparent in the data, though the exact form of the resulting specification is still under debate. (See Rotemberg and Woodford, 1999; Fuhrer, 2000; McCallum and Nelson, 1999; Estrella and Fuhrer, 1998, and Svensson 1999a.) Section 3 discusses related empirical evidence on the size of the parameters $\mu_{\pi}, \mu_{y}$, and $\mu_{r}$.

The model is closed with the Taylor (1993) monetary policy rule,

$$
i_{t}=g_{\pi} \pi_{t}+g_{y} y_{t}+\xi_{t}
$$

which is a specific version of the above $G$ function used by Lucas (1976), with the $\lambda$ parameter vector consisting of $g_{\pi}$ and $g_{y}$, and a random policy shock $\xi_{t}$.

For the lagged expectational model and this policy rule, the reduced form for the output gap can be written as

$$
y_{t}=\theta_{y} y_{t-1}+\theta_{i} i_{t-1}+\theta_{\pi} \pi_{t-1}+\eta_{t}
$$


where $\theta_{y}, \theta_{i}$, and $\theta_{\pi}$ are the reduced form parameters in equation (2.1) from Lucas (1976). If $\mu_{\pi}=\mu_{y}=\mu_{r}=0$, the model is completely backward-looking, so the Lucas critique will not apply. In this case, $\theta_{y}=\beta_{y}$ and $\theta_{i}=-\theta_{\pi}=-\beta_{r}$ and are independent of the policy parameters. In the general case, Lansing and Trehan (2001) derive the parameters of the reduced form output gap equation under the assumption of rational expectations as

$$
\theta_{y}=\left[\frac{\beta_{y}\left(1-\mu_{y}\right)-\beta_{r} \mu_{r}\left(\frac{\alpha_{y}}{1-\mu_{\pi}}\right)\left(g_{\pi}-1\right)}{1-\beta_{y} \mu_{y}+\beta_{r} \mu_{r} g_{y}}\right] ; \theta_{i}=-\left[\frac{\beta_{r}\left(1-\mu_{r}\right)}{1-\beta_{y} \mu_{y}+\beta_{r} \mu_{r} g_{y}}\right] ; \theta_{\pi}=\left[\frac{\beta_{r}\left(1-\mu_{r} g_{\pi}\right)}{1-\beta_{y} \mu_{y}+\beta_{r} \mu_{r} g_{y}}\right] .
$$

With non-zero $\mu_{\pi}, \mu_{y}$, and $\mu_{r}$, the reduced form parameters $\theta_{y}, \theta_{i}$, and $\theta_{\pi}$ depend on the policy rule parameters $g_{\pi}$ and $g_{y}$, so an empirical backward-looking output equation will not be stable across different monetary policy rules. ${ }^{5}$

Highlighting the dependence of the reduced form on $g_{\pi}$ and $g_{y}$ is the point of Lucas (1976). However, although different policy rules result in different reduced form dynamics, assessing the importance of the Lucas critique requires quantifying this dependence. In a given sample, the reduced form may appear to be stable for at least two reasons. First, the changes in policy may be negligible; that is, $\Delta g_{\pi}$ and $\Delta g_{y}$ are so small that the reduced form parameters are essentially invariant. Second, the link between the reduced form coefficients and the policy parameters may be too weak; that is, the partial derivatives $\partial \theta_{j} / \partial g_{k}$, for $j=y, i$, or $\pi$ and $k=\pi$ or $y$, may be too small to induce detectable changes. ${ }^{6}$

Table 1 quantifies the Lucas critique for the lagged expectational model using the coefficients of the output reduced form (2.10). Three different policy rules are considered, with either a weak or strong output gap response, $g_{y}=0.5$ or 1.0 , and either a weak or strong inflation response, $g_{\pi}=1.1$ or 2.5. As shown below, these changes in the policy rule parameters are roughly the same size as the changes in the estimated policy rule coefficients in the United States. Because the importance of expectations is crucial for assessing the Lucas critique, four different parameterizations are considered with a wide range of possible values for $\mu_{\pi}, \mu_{y}$, and $\mu_{r}$. First, an autoregressive model with $\mu_{\pi}=\mu_{y}=\mu_{r}=0$ is shown in the top three rows of Table 1. Of course, for this model, the changes in the policy rule parameters have no effect on the reduced form coefficients. Second, two partially forward-looking intermediate models are considered - with $\mu_{\pi}=0.3, \mu_{y}=0.1$, and $\mu_{r}=0.5$ and with $\mu_{\pi}=0.5, \mu_{y}=0.3$, and $\mu_{r}=0.9$.

\footnotetext{
${ }^{5}$ In contrast, as Lansing and Trehan (2001) note, because of the lagged formation of expectations in this model, the inflation reduced form is unaffected by changes in the policy rule.

${ }^{6}$ Of course, possibilities not considered in this framework are expectations that are less than fully rational or policy commitment that is less than complete.
} 
As discussed below, these parameter values are inside the range of empirical estimates that have been obtained. Finally, an extreme expectational model - with $\mu_{\pi}=\mu_{y}=0.8$ and $\mu_{r}=0.9$-is also considered.

The other parameters in the model - the interest rate sensitivity, $\beta_{r}$, the persistence of output, $\beta_{y}$, and the slope of aggregate supply, $\alpha_{y}$-are less contentious empirically, and they are calibrated to approximate typical empirical values (discussed below), with $\beta_{r}=0.1, \beta_{y}=0.95$, and $\alpha_{y}=0.1$. Inspection of the reduced form (2.10) suggests that the partials $\partial \theta_{j} / \partial g_{k}$, for $j=y, i$, or $\pi$ and $k=\pi$ or $y$, do not significantly depend on $\beta_{y}$ and $\alpha_{y}$, and, indeed, plausible variation in these two parameters does not appreciably alter the results in Table 1 regarding the importance of the Lucas critique. In contrast, variation in $\beta_{r}$ is quite important, as nearly all of the partials, $\partial \theta_{j} / \partial g_{k}$, depend directly on the size of $\beta_{r}$. Intuitively, with a large $\beta_{r}$, the economy is very responsive to movements in the policy rate; therefore, changes in the policy rule have magnified effects on the reduced form dynamics. To illustrate this effect, Table 1 also provides the reduced form coefficients assuming that $\beta_{r}=0.2$.

Consider first the extreme example of the forward-looking model with $\mu_{\pi}=\mu_{y}=0.8$ and $\mu_{r}=0.9$. As shown in the bottom rows of Table 1 , in this case, there are fairly large changes in the reduced form across the three policy rules. Furthermore, when $\beta_{r}=0.2$ (the columns on the right) the effects of the changes in the policy rule are at times almost twice as large as when $\beta_{r}=0.1$ (the middle columns). For example, the range of variation in $\theta_{y}$ is 0.28 across the three policy rules when $\beta_{r}=0.1$, but it is 0.42 when $\beta_{r}=0.2$. The intermediate expectational models in the middle rows of Table 1 (with $\mu_{\pi}=0.3, \mu_{y}=0.1$, and $\mu_{r}=0.5$ and with $\mu_{\pi}=0.5$, $\mu_{y}=0.3$, and $\left.\mu_{r}=0.9\right)$ give similar but much more moderate results.

In Table 1, models with larger expectational weights demonstrate larger Lucas critique effects (i.e., larger policy-induced changes in the reduced form). However, this result is not general and does not hold, for example, in the contemporaneous expectational model:

$$
\begin{gathered}
y_{t}=\beta_{y}\left[\left(1-\mu_{y}\right) y_{t-1}+\mu_{y} E_{t} y_{t+1}\right]-\beta_{r} r_{t-1}+\eta_{t}, \\
r_{t-1}=\left(1-\mu_{r}\right)\left(i_{t-1}-\pi_{t-1}\right)+\mu_{r}\left(i_{t}-E_{t} \pi_{t+1}\right), \\
\pi_{t}=\left(1-\mu_{\pi}\right) \pi_{t-1}+\mu_{\pi} E_{t} \pi_{t+1}+\alpha_{y} y_{t-1}+\varepsilon_{t} .
\end{gathered}
$$

In this model, the timing of expectations formation differs from equations (2.3), (2.4), and (2.5) but is closer to the usual New Keynesian specification. Specifically, the inflation equation uses 
a "sticky price" $E_{t} \pi_{t+1}$ formulation, rather than a "sticky information" $E_{t-1} \pi_{t}$ formulation in the lagged expectational model (see Mankiw and Reis, 2001). Also, the timing of expectations formation in the output equation matches the consumption Euler equation, with $y_{t}$ depending on $E_{t} y_{t+1}$, rather than $E_{t-1} y_{t}$, and on $i_{t}-E_{t} \pi_{t+1}$, rather than $E_{t-1}\left(i_{t}-\pi_{t}\right)$. This contemporaneous expectational model also can capture a wide range of explicit forward-looking behavior through variation in the parameters $\mu_{\pi}, \mu_{y}$, and $\mu_{r}$.

When coupled with the policy rule (2.8), the contemporaneous expectational model has a general reduced form of

$$
\left[\begin{array}{c}
y_{t} \\
\pi_{t} \\
i_{t}
\end{array}\right]=B_{1}\left[\begin{array}{c}
y_{t-1} \\
\pi_{t-1} \\
i_{t-1}
\end{array}\right]+B_{0}\left[\begin{array}{c}
\varepsilon_{t} \\
\eta_{t} \\
\xi_{t}
\end{array}\right] .
$$

In this model, changes in the policy rule affect the coefficients of the reduced form $\left(B_{1}\right)$ and the covariance matrix of the reduced-form errors (through variation in $\left.B_{0}\right){ }^{7}$ Table 2 displays this variation for the output and inflation reduced forms, which are re-written,

$$
\begin{gathered}
y_{t}=b_{y y} y_{t-1}+b_{y \pi} \pi_{t-1}+b_{y i} i_{t-1}+b_{y \varepsilon} \varepsilon_{t}+b_{y \eta} \eta_{t}+b_{y \xi} \xi_{t} \\
\pi_{t}=b_{\pi y} y_{t-1}+b_{\pi \pi} \pi_{t-1}+b_{\pi i} i_{t-1}+b_{\pi \varepsilon} \varepsilon_{t}+b_{\pi \eta} \eta_{t}+b_{\pi \xi} \xi_{t} .
\end{gathered}
$$

A analytical solution is unavailable, so the parameter values were obtained numerically assuming that $\beta_{r}=0.1, \beta_{y}=0.95$, and $\alpha_{y}=0.1 .^{8}$ As in Table 1 , four different structural models with varying expectation weights $\left(\mu_{\pi}, \mu_{y}\right.$, and $\left.\mu_{r}\right)$ are considered, along with three different monetary policy rules with varying response coefficients $\left(g_{\pi}\right.$ and $\left.g_{y}\right)$. For the three forward-looking models, the dependence of the reduced forms on the policy rule is clear. However, the magnitude of the parameter shifts remains fairly low. Furthermore, unlike for the lagged expectational model, the size of the response of the reduced form parameters to policy shift is not strictly increasing as the expectational weights increase. This result reflects the extreme stationarity of the very forwardlooking model under policy commitment and is discussed further in the empirical application below.

Overall, the Lucas critique clearly operates in both of these theoretical models. However, the results in Tables 1 and 2 highlight the question of whether the policy-induced changes in the reduced form are economically and statistically significant. That is, are changes in the reduced

\footnotetext{
${ }^{7}$ The application of the Lucas critique to the covariance matrix of the reduced form shocks is perhaps underappreciated, though see Walsh (1984) for early discussion.

8 The parameter values were obtained numerically using the AIM algorithm, which solves dynamic linear rational expectations models and is described in Anderson and Moore (1985) and at http://www.federalreserve.gov/pubs/oss/oss4/aimindex.html.
} 
form important by some economic metric? And, can policy-induced changes in the reduced form be detected statistically in a given sample of macroeconomic data. As usual in econometrics, the answers to these question may differ. In any case, answering these questions about the economic and statistical importance of the Lucas critique in the real world, requires obtaining models and rules that are empirically based, as provided in the next two sections.

\section{Empirical Monetary Policy Models}

New Keynesian models of the kind illustrated above allow expectations of policy to play an important role in the determination of the reduced form. Much of the appeal of these models lies in their theoretical foundation, but there have also been empirical implementations, including Fuhrer (2000) and Rudebusch (2002). ${ }^{9}$ For estimation with quarterly data, some modification of the above equations seems appropriate. In particular, given the observed length of real world contracts, delays in information flows, and decision lags, an expanded model with longer quarterly leads and lags is specified here as

$$
\begin{aligned}
& y_{t}=\mu_{y} E_{t-1} y_{t+1}+\left(1-\mu_{y}\right) \Sigma_{j=1}^{2} \beta_{y j} y_{t-j}-\beta_{r} r_{t-1}+\eta_{t}, \\
& r_{t-1}=\mu_{r}\left(E_{t-1} \bar{\imath}_{t+3}-E_{t-1} \bar{\pi}_{t+4}\right)+\left(1-\mu_{r}\right)\left(\bar{\imath}_{t-1}-\bar{\pi}_{t-1}\right), \\
& \pi_{t}=\mu_{\pi} E_{t-1} \bar{\pi}_{t+3}+\left(1-\mu_{\pi}\right) \Sigma_{j=1}^{4} \alpha_{\pi j} \pi_{t-j}+\alpha_{y} y_{t-1}+\varepsilon_{t},
\end{aligned}
$$

where $\bar{\pi}_{t}$ is the four-quarter inflation rate, and $\bar{\imath}_{t}$ is a four-quarter average of past interest rates (i.e., $\bar{\pi}_{t}=\frac{1}{4} \Sigma_{j=0}^{3} \pi_{t-j}$ and $\bar{\imath}_{t}=\frac{1}{4} \Sigma_{j=0}^{3} i_{t-j}$ ). Thus, $E_{t-1} \bar{\pi}_{t+3}$ represents the expectation of average inflation over the next year, and $r_{t-1}$ is defined as a weighted combination of an ex ante one-year rate and an ex post one-year rate. ${ }^{10}$

As above, this model allows consideration of a wide range of explicit forward-looking behavior in the determination of inflation and output by varying the values of $\mu_{\pi}, \mu_{y}$, and $\mu_{r}$. Empirical evidence on the values of $\mu_{\pi}, \mu_{y}$, and $\mu_{r}$ in this model and other similar ones has been decidedly mixed. A completely backward-looking model with $\mu_{\pi}=\mu_{y}=\mu_{r}=0$ has had some success in approximating the U.S. data, as shown in Rudebusch and Svensson (1999), Rudebusch (2001a), and Estrella and Fuhrer (1998). The many available empirical estimates described in Rudebusch

\footnotetext{
${ }^{9}$ I have conducted the analysis below with the Fuhrer (2000) model and obtained similar results.

10 With quarterly data, expectations in this model are a hybrid of the two theoretical models presented above, which are often considered at an annual frequency. In particular, although expectations are formed in quarter $t-1$, which seems reasonable given real-world lags, agents do look forward beyond time $t$.
} 
(2002) suggest that a very broad plausible range for $\mu_{\pi}$ is between 0 and 0.6. For example, Fuhrer (1997) estimates $\mu_{\pi}$ to be about zero, Rudebusch (2002) estimates $\mu_{\pi}=0.3$, while Fuhrer and Moore (1995) assume $\mu_{\pi}=0.5$. For $\mu_{r}$, which governs the forward-looking behavior in interest rates that is relevant for output determination, it is hard to obtain any decisive empirical evidence on an appropriate value given the colinearity of many interest rates (e.g., Fuhrer and Moore, 1995). For $\mu_{y}$, almost all empirical estimates have assumed a value of zero (e.g., Fuhrer and Moore, 1995); however, the estimated habit persistence model of Fuhrer (2000) suggests a $\mu_{y}$ approximately equal to 0.3 (see Rudebusch, 2002).

In order to consider a broad range of possible expectational behavior, the analysis below focuses on four different models:

- A completely autoregressive Model 0 , with $\mu_{\pi}=\mu_{y}=\mu_{r}=0$;

- A modestly forward-looking Model 1, with $\mu_{\pi}=0.3, \mu_{y}=0.1$, and $\mu_{r}=0.5$;

- A very forward-looking Model 2, with $\mu_{\pi}=0.5, \mu_{y}=0.3$, and $\mu_{r}=0.9$;

- An extremely forward-looking Model 3, with $\mu_{\pi}=0.8, \mu_{y}=0.8$, and $\mu_{r}=0.9$.

At a loose level, Models 0, 1, and 2 all appear largely consistent with the data. Model 3, on the other hand, appears implausibly forward-looking (see Estrella and Fuhrer, 2000, and Rudebusch, 2002) and is included to provide an extreme expectational model in which to assess the Lucas critique.

The other parameters in the model equations (3.1) and (3.3) are set equal to the values given in Table 3. These specific parameter values - and their associated standard errors - match the estimates given in Rudebusch (2002) that are obtained from postwar U.S. data. ${ }^{11}$ Others have provided very similar parameter estimates with different data definitions and with slight variations of the model (see Clark, Laxton, and Rose, 1996, Rudebusch, 2001a, Smets, 1999, Laubach and Williams, 2001). The robustness of the results to variation in these parameters is discussed below.

\section{Empirical Monetary Policy Rules}

As a second element, an empirical assessment of the Lucas critique also requires a plausible change in the policy rule. Many recent studies have estimated models of central bank behavior

11 The specific data constructions used are as follows. The interest rate $i_{t}$ is the quarterly average overnight funds rate in percent. Quarterly inflation is annualized and in percent, so using the GDP chain-weighted price index (denoted $\left.P_{t}\right), \pi_{t}=400\left(\ln P_{t}-\ln P_{t-1}\right)$. The output gap is defined as the percent difference between real $\operatorname{GDP}\left(Q_{t}\right)$ and potential output $\left(Q_{t}^{*}\right)$ as estimated by the Congressional Budget Office (i.e., $\left.y_{t}=100\left(Q_{t}-Q_{t}^{*}\right) / Q_{t}^{*}\right)$. 
based on the Taylor rule (2.8). Furthermore, almost all of these have allowed for a structural shift in the specification of U.S. monetary policy between the early postwar period and the past decade or two.

For example, Taylor (1999, p. 330) estimates equation (2.8) and finds that from 1960:Q1 through 1979:Q4 the Federal Reserve followed the rule (ignoring constants)

$$
i_{t}=\underset{(.06)}{.81 \bar{\pi}_{t}}+\underset{(.05)}{.25 y_{t}}+\xi_{t},
$$

where the coefficient standard errors are given in parentheses. In contrast, over the period 1987:Q1 through 1997:Q3, Taylor estimates the rule

$$
i_{t}=\underset{(.16)}{1.53 \bar{\pi}_{t}}+\underset{(.09)}{.77 y_{t}}+\xi_{t} .
$$

Taylor (1999) focuses on the large economic differences between these two rules. However, given the large numerical differences in the coefficients relative to their standard errors, a formal statistical test of the null of no change would clearly be rejected. Below, these two estimated rules (4.1) and (4.2), which will be denoted as the Ta and $\mathrm{Tb}$ rules, respectively are each incorporated into a New Keynesian model, and the resulting reduced forms are compared.

Other authors have estimated similar rules but with added dynamics and different variables. For example, Clarida, Gali, and Gertler (2000, p. 161) estimate a specification of the Taylor rule in which the Fed sets the average funds rate in quarter $t$ in response to forecasts of inflation and the output gap based on information at time $t-1$. For the period 1960:Q1 through 1979:Q2, they estimate a rule:

$$
i_{t}=.27\left(.86 E_{t-1} \bar{\pi}_{t+4}+.34 E_{t-1} y_{t}\right)+.73 i_{t-1}+\xi_{t},
$$

and for the later period 1979:Q3 through 1996:Q4, they estimate

$$
i_{t}=.22\left(2.62 E_{t-1} \bar{\pi}_{t+4}+.83 E_{t-1} y_{t}\right)+.78 i_{t-1}+\xi_{t} .
$$

The response coefficients associated with these forecast-based rules are higher than in the Ta and $\mathrm{Tb}$ rules, which is not surprising given the smoothness of forecasts relative to actual outcomes. Also, the lagged interest term is extremely helpful in fitting the persistent dynamics of the interest rate. ${ }^{12}$ These two estimated rules (4.3) and (4.4) give an alternative view of postwar

\footnotetext{
${ }^{12}$ Note, however, that such lagged dynamics are often given a partial adjustment or interest rate smoothing interpretation that has been discredited by Rudebusch (2001b) using term structure evidence. Also, this specification is a minor simplification over the one in Clarida, Gali, and Gertler (2000) because they include two lags of the interest rate; however, since they only report the sum of the lag coefficients, the two lags have been collapsed into one.
} 
U.S. monetary policy to be considered, which I denote as the CGGa and the CGGb rules, respectively.

Finally, Estrella and Fuhrer (2000) use another empirical variant of the Taylor rule in their study of the stability of macroeconomic relationships. They find a very significant structural break in the policy rule just after 1980:Q3. Estimated over the early 1966:Q1 through 1980:Q3 sample, ${ }^{13}$ their reaction function-denoted $\mathrm{EFa}$ - is

$$
i_{t}=\underset{(.34)}{.29\left(.46 \bar{\pi}_{t-1}\right.}+\underset{(.29)}{\left.1.03 y_{t-1}\right)}+\underset{(.13)}{1.18 i_{t-1}}-\underset{(.13)}{.47 i_{t-2}}+\xi_{t} \text {, }
$$

while estimated over 1980:Q4 to 1996.Q4 - the EFb rule - the results are

$$
i_{t}=\underset{(.27)}{.31\left(1.88 \bar{\pi}_{t-1}\right.}+\underset{(.25)}{\left..46 y_{t-1}\right)}+\underset{(.13)}{.77 i_{t-1}}-\underset{(.12)}{.08 i_{t-2}}+\xi_{t} .
$$

These six rules - $\mathrm{Ta}, \mathrm{Tb}, \mathrm{CGGa}, \mathrm{CGGb}, \mathrm{EFa}$, and $\mathrm{EFb}$ - give a wide range of estimates for historical changes in the policy rule. ${ }^{14}$ As has been stressed by their various authors, there appear to be significant statistical and economic differences between these early-sample and later-sample rules, so they provide a excellent framework for an exploration of the Lucas critique.

\section{The Empirical Relevance of the Lucas Critique}

The equations of the autoregressive, nonexpectational Model 0 (equations (3.1), (3.2), and (3.3) with $\mu_{\pi}=\mu_{y}=\mu_{r}=0$ ) can be written

$$
\begin{gathered}
y_{t}=\beta_{y 1} y_{t-1}+\beta_{y 2} y_{t-2}-\beta_{r}\left(\bar{\imath}_{t-1}-\bar{\pi}_{t-1}\right)+\eta_{t}, \\
\pi_{t}=\sum_{j=1}^{4} \alpha_{\pi j} \pi_{t-j}+\alpha_{y} y_{t-1}+\varepsilon_{t} .
\end{gathered}
$$

These equations are a surprisingly popular framework for monetary policy analysis (e.g., Rudebusch and Svensson, 1999, 2002, Smets, 1999, Onatski and Stock, 2002, Laubach and Williams, 2001, and Dennis, 2001). They are also precisely the type of model that Lucas (1976) cautioned against in conducting policy rule evaluations. If economic agents are rationally forward-looking,

\footnotetext{
${ }^{13}$ Estrella and Fuhrer (2000) do not actually provide sub-sample coefficient estimates. I replicated their full sample estimates and then produced analogous sub-sample ones.

${ }_{14}$ Another way to model central bank behavior is to specify the central bank objective function directly rather than estimating a reaction function. (That is, a targeting rule rather than an instrument rule, as described in Rudebusch and Svensson, 1999.) In this interpretation of postwar U.S. monetary policy, one factor for the differential inflation performance in the 1970s versus the 1980s may have been the lower weight on output stabilization, $\lambda$, during the latter period (Judd and Rudebusch, 1998). I obtained similar results to those below with optimal Taylor rules for each model assuming a loss function with $\lambda=4$ for the earlier "a" period and $\lambda=0.25$ for the latter "b" period.
} 
then, according to the Lucas critique, the parameters of this model will be unstable across different policy regimes just as were the parameters of the reduced forms in Section 2.

The key issue, however, is the economic and statistical importance of this instability. To investigate these questions, the Model 0 equations (5.1) and (5.2) are estimated on simulated data drawn from repeated samples with varying policy regimes, and the resulting autoregressive coefficient estimates are examined for instability. Four different models - the Models 0, 1, 2, and 3 above -are used to generate these data samples. ${ }^{15}$ Of course, when Model 0 generates the data, equations (5.1) and (5.2) will be properly specified and stable across policy regimes. However, if an expectational Model 1, 2, or 3 generates the data, then the parameters of the estimated Model 0 will be unstable across different policy regimes. In each data sample, 120 observations are generated from a particular model with a first-half policy rule, and then 120 observations are generated from that same model with a second-half policy rule. ${ }^{16}$ Thus, the (potentially forward-looking) structural output and inflation equations of the data generating process are held fixed throughout the sample.

Each policy rule is assumed to be perfectly credible during its own regime; that is, agents know the rule and assume that it will be followed. Specifically, in each policy regime, the unique stationary rational expectations "commitment" solution for the policy rule is used to generate data (using the AIM algorithm as above). Thus, observations are generated on the assumption that the change in the rule is completely unanticipated but is immediately recognized after it takes place. Of course, any learning or uncertainty about the regime would make it more difficult to detect the policy shift in the estimated equations (unknown breakpoint tests would have to be used, for example), so this experiment maximizes the ability to detect structural shifts.

This methodology also limits the analysis to consideration of only stationary combinations of policy rules and structural models. However, some of the above estimated rules induce dynamic instability, specifically, the Ta and CGGa rules, which have long-run inflation response coefficients of 0.81 and 0.86 , respectively. These coefficients violate the intuitive rule that nominal interest rates must respond by more than one-for-one to changes in inflation in order to control

\footnotetext{
15 The data are constructed and Model 0 equations are estimated with no constants. The shift in postwar monetary policy may have included a decrease in the inflation target, which would imply a shift in the Taylor rule constant and a shift in the estimated constant in the inflation reduced form. This obvious Lucas critique effect in constant terms is not considered. Furthermore, note that a perceived shift in the equilibrium real rate would change constants in the policy rule and the output reduced form in a fashion that would spuriously suggest a Lucas critique effect.

${ }_{16}$ The initial conditions for the first policy rule sample are random draws from their unconditional distribution. The initial conditions for the second policy rule sample are the last few observations of the first sample.
} 
the economy (the so-called "Taylor principle"). Of course, the researchers who produced these empirical estimates argue that historically the Fed could have followed these unstable rules at first and then switched to a stable rule when the economy started to get out of control. Indeed, this is one interpretation of the U.S. experience during the 1970s and 1980s. However, unstable rules are problematic for this assessment of the Lucas critique, which contrasts the reduced forms from different policy rules under the assumption that at any given time the prevailing policy rule is permanent. ${ }^{17}$ This methodology requires stable systems. Therefore, to induce stability, the inflation response coefficients in the Ta and CGGa rules are adjusted up by about 30 percent to 1.1. (Clarida, Gali, Gertler, 2000, make a similar adjustment.) To maintain the approximate difference between the first and second sample rules, the inflation response coefficients for the $\mathrm{Tb}$ and CGGb rules are also boosted up by about 30 percent to 2.1 and 3.4, respectively. All results below use these redefined rules.

Also, it is worth noting that Model 0 represents a particular autoregressive model with limits on the number of lags and other restrictions. This representation is a quasi-reduced form that only approximates the true reduced form of the forward-looking model. Of course, in practice, the econometrician does not know the correct specification of the reduced form, and so examining the stability of this popular autoregressive model is useful. In any case, essentially identical results were obtained using an unrestricted VAR with four lags as the estimated reduced form.

Table 4 provides statistical evidence on the detectability of Lucas critique instability in this framework. Each entry in the table provides the proportion of 5,000 repeated samples in which the Chow test statistic exceeded the 5 percent theoretical critical value, which indicates rejection of the null hypothesis of structural stability. ${ }^{18}$ Roughly speaking, these are $p$-values for the rejection of the stability null, and can be used to assess both the size and power of the Chow test.

First, consider the empirical size of the test. In the top two rows of Table 4, the policy rule Ta is used in both the first and second halves of each sample, so there is no instability in the

\footnotetext{
${ }^{17}$ Obviously, Lucas' dynamic optimization problem cannot be constructed for an unstable system. This problem highlights the contention of Sims(1982) that Lucas (1976) is based on an unrealistic situation where policy rules that may change are considered permanent. If agents realize that policymakers probabilistically switch between two alternative rules, then even if one of the rules is dynamically unstable, the complete system may not be.

18 For each model and rule combination, 5,000 samples of 120 observations are generated using normally distributed structural shocks with the standard errors shown in Table 2. The policy rule is assumed to be followed without error. The results were essentially unchanged to variation in the variances of the structural shocks or to added policy noise. Also, similar results were obtained for other combinations of the rules such as a first sample Ta rule and a second sample CGGb rule.
} 
data generating process. Both the output and inflation equations of the autoregressive Model 0 are estimated (by single-equation OLS) for the whole sample and for each half. The proportion of rejections for Model 0 with the Ta rule used in each half are 5 percent for the output equation and 4.6 percent for inflation, so the Chow test is well sized in this case (empirical size is close to nominal size). Indeed, the Chow test was also well sized when the Tb, CGGa, CGGb, EFa, and $\mathrm{EFb}$ rules were used in both halves of the sample (the Tb results are shown in lines 3 and 4, while the other results are omitted to save space).

Panel B in Table 4 provides results when the policy rule differs across the first and second halves of the sample. However, Model 0 column of results continues to reflect the size of the Chow test. As noted above, even when the policy rule is changed during the sample, the Model 0 data generating process is autoregressive, so the estimated Model 0 coefficients should be identified as stable. Indeed, all the Model 0 generated $p$-values are close to 5 percent, so the theoretical critical values for the Chow test appear appropriate.

The results for the forward-looking Models 1, 2, and 3 in Panel B go to the heart of the Lucas critique. These $18 p$-values indicate the likelihood of rejecting the (incorrect) null of structural stability. If the Lucas critique were important statistically, then there would be significant differences among the quasi-reduced-form Model 0 output and inflation equations that were estimated from expectational systems with changing monetary policy rules. However, the median $p$-value in this block of entries is 0.06 , so on average the power of the Chow test in this case is not very different from the nominal size of the 5 percent test. The maximum proportion of rejections is 15.8 percent for the output equation and 13.4 percent for the inflation equation-little evidence of a structural break. Thus, in this setting, there appears to be little evidence that the Lucas critique can be detected statistically.

However, the fact that changes in the estimated Model 0 coefficients induced by the policy shifts cannot be detected statistically may reflect the low power of the Chow test. ${ }^{19}$ Furthermore, some changes in the reduced form that are not detected statistically may be important economically. To examine this second issue of economic importance, Table 5 reports the average coefficient estimates of Model 0 for the three expectational models and the six different policy rules. For each combination, the averages are based on 5,000 samples of 120 observations, with standard errors given in parentheses. The first two columns list the model and the rule used to

\footnotetext{
${ }^{19}$ Again, however, the correct breakpoint is assumed known, which unrealistically boosts the ability of the test to detect a breakpoint.
} 
generate the data. The next three columns give the average estimates of the output equation parameters: the own-lag coefficients, $\beta_{y 1}$ and $\beta_{y 2}$, and the interest rate sensitivity, $\beta_{r}$. The next four columns give the average estimates of the inflation equation parameters: the own-lag coefficients, $\alpha_{\pi 1}, \alpha_{\pi 2}, \alpha_{\pi 3}$, and $\alpha_{\pi 4}$, and the slope coefficient $\alpha_{y}$. The final column gives the average sum of the own-lag inflation coefficients, $\sum_{j=1}^{4} \alpha_{\pi j}$.

For a given model, the differences in the parameter estimates across various rows are quite small in relation to the standard errors, which confirms the Chow test results in Table 4. However, from Table 5, it is also clear that the numerical differences between the various reduced forms for any one of the three structural models are economically quite modest. The Chow test results are not being driven by large standard errors but by small differences in the reduced form coefficients.

As an example, consider a thought experiment in which a policymaker follows one of the six empirical policy rules for 30 years and then estimates Model 0 on the resulting data. Would the dynamics of that estimated Model 0 depend importantly on the specific policy rule employed during the sample? The analysis of Sargent (1999) suggests that the estimated dynamics would vary significantly with the policy rule. As a metric, Sargent (1999) uses the sum of the own-lag coefficients in the inflation equation, the $\sum_{j=1}^{4} \alpha_{\pi j}$. (In certain situations, whether this sum equals one suggests whether the natural rate hypothesis is true.) Sargent argues that this sum will vary greatly as the monetary policy rule is changed. ${ }^{20}$ In fact, for the empirically relevant models and rules considered here, the variation appears quite modest. Across the policy rules, the range of variation in the average estimated of this sum is only $0.04,0.18$, and 0.13 for Models 1,2 , and 3 , respectively. ${ }^{21}$

The policymaker also could examine the dynamics of the resulting reduced forms by investigating the impulse responses of shocks. Would estimated impulse response functions depend on the policy rule followed in the past? Figures 1, 2, and 3 provide the impulse responses of the average Model 0 estimates given in Table 5 for Models 1, 2, and 3, respectively. In each panel, there are three solid line impulse responses that correspond to the Model 0 estimates obtained from

\footnotetext{
${ }^{20}$ Indeed, there is a cyclical dynamic in Sargent's story because the lag coefficient sum varies as U.S. monetary policymakers alter the policy rule based on their beliefs about the validity of the natural rate hypothesis, and these beliefs are derived from an inspection of the the sum of the lag coefficients.

${ }^{21}$ Note that the size of the variation does not increase monotonically with the expectational weights, which is similar to the result obtained in Table 2. These smaller changes in the reduced form also are reflected in the fact that the power of the Chow test does not increase monotonically with the expectational weights in Table 4 . From the impulse responses in Figure 3, it is clear that Model 3 reverts to the steady state very quickly after a shock regardless of the policy rule.
} 
the earlier sample Ta, EFa, and CGGa policy rules, and three dashed line impulse responses that correspond to the Model 0 estimates obtained from the later sample Tb, EFb, and CGGb rules. In each case, the system includes the Model 0 output and inflation equations and the EFb rule; thus any differences among the impulse responses reflects the indirect expectational effects of the different policy rules on the autoregressive structure for output and inflation. The responses show reactions to one percentage point shocks to inflation, output, and the funds rate. There are some quantitative differences among dynamics of the average quasi-reduced-form models; however, these differences are quite small.

Finally, an examination of the robustness of these results was also undertaken in a variety of dimensions: (1) perturbing the parameters of the data generating process from their values in Table 3, (2) changing the size of the shocks to the system, (3) varying the sample size, and (4) changing the form of the quasi-reduced form. These perturbations generally had small effects on the results with one notable exception. As suggested by the theoretical analysis in Section 2, the parameter governing the interest rate sensitivity of the economy, $\beta_{r}$, was very influential. This influence is shown in Table 6, which provides $p$-values for the stability null hypothesis identical to those in Table 3 except that the data generating models use $\beta_{r}=0.2$ instead of 0.09 . This is a fairly extreme value given typical empirical estimates and standard errors (although many economists appear to believe that interest rate elasticities are higher than the data suggest, say for business investment and labor supply). ${ }^{22}$ The Chow test remains well-sized in this case (Panel A) and is significantly more likely to detect a structural shift in the policy rule in the expectational models (Panel B). However, the power of the test to detect the Lucas critique never rises above 50 percent.

\section{Conclusion}

At a theoretical level, the Lucas critique is uncontested: Reduced form models are not invariant to policy-induced structural changes. However, the empirical relevance of this critique is in some dispute. This paper examines the stability of commonly used autoregressive empirical representations that are estimated using simulated data generated from empirical expectational models with historical policy rule shifts. There is little evidence that the Lucas critique is an important factor in this setting given typical macroeconomic sample sizes (confirming, for

\footnotetext{
${ }^{22}$ The estimate of $\beta_{r}$ in Rudebusch (2002) is 0.09 with a standard error of 0.03 (shown in Table 2). Clark, Laxton, and Rose (1996) and Smets (1999) estimate $\beta_{r}$ of 0.16 and 0.9 , respectively.
} 
example, Taylor, 1984, 1989). In short, these results reconcile the use of autoregressive models, such as VARs, with the empirical results on policy rule shifts and the Lucas critique. Of course, there are parameter configurations and rule shifts that would give the Lucas critique more importance. Indeed, although a particular autoregressive representation may be roughly invariant to observed policy shifts, it would not necessarily be a suitable model for a policy analysis that considered shifts in policy rules that lie outside the historical experience.

It is unlikely that the inability to detect structural shifts in the reduced form stems from the low power of the statistical test. As noted above, such tests apparently are able to detect structural breaks in the Fed's reaction function. Furthermore, these tests have rejected the null of stability for a variety of other macroeconomic models. Ironically, some of these rejections have occurred for models with "deep" parameters that were developed in response to the Lucas critique. Notably, Oliner, Rudebusch, and Sichel (1996), Swaine (2001), and Estrella and Fuhrer (2000) reject the null of stability, respectively, for an Euler equation, an explicit optimizing general equilibrium model, and a very forward-looking New Keynesian model. That is, there are many models, including some that have been specifically created to be structural models, for which the statistical break tests do have power to detect instability.

There are several other reasons why an autoregressive model may appear stable in practice and why the Lucas critique would not appear to apply. For example, shifts in the policy rule may be unimportant historically. This explanation is at odds with almost all of the empirical policy rules literature and is not entertained here. Instead, the above results suggest that autoregressive models are relatively insensitive to significant changes in the policy rule. This insensitivity could occur if expectations were adaptive, of course, but, as demonstrated above, it can also occur in empirically relevant models with rational expectations. 
Table 1

Output Reduced Form for Lagged Expectational Structural Model

\begin{tabular}{|c|c|c|c|c|c|c|c|c|c|c|}
\hline \multicolumn{3}{|c|}{ Model } & \multicolumn{2}{|c|}{ Rule } & \multicolumn{3}{|c|}{ Reduced Form $\left(\beta_{r}=.1\right)$} & \multicolumn{3}{|c|}{ Reduced Form $\left(\beta_{r}=.2\right)$} \\
\hline$\mu_{r}$ & $\mu_{\pi}$ & $\mu_{y}$ & $g_{y}$ & $g_{\pi}$ & $\theta_{y}$ & $\theta_{i}$ & $\theta_{\pi}$ & $\theta_{y}$ & $\theta_{i}$ & $\theta_{\pi}$ \\
\hline 0 & 0 & 0 & .5 & 1.1 & .95 & -.10 & .10 & .95 & -.20 & .20 \\
\hline 0 & 0 & 0 & .5 & 2.5 & .95 & -.10 & .10 & .95 & -.20 & .20 \\
\hline 0 & 0 & 0 & 1.0 & 2.5 & .95 & -.10 & .10 & .95 & -.20 & .20 \\
\hline .5 & .3 & .1 & .5 & 1.1 & .92 & -.05 & .05 & .89 & -.10 & .09 \\
\hline .5 & .3 & .1 & .5 & 2.5 & .91 & -.05 & -.03 & .87 & -.10 & -.05 \\
\hline .5 & .3 & .1 & 1.0 & 2.5 & .88 & -.05 & -.02 & .83 & -.10 & -.05 \\
\hline .9 & .5 & .3 & .5 & 1.1 & .87 & -.01 & .00 & .82 & -.02 & .00 \\
\hline .9 & .5 & .3 & .5 & 2.5 & .84 & -.01 & -.16 & .76 & -.02 & -.31 \\
\hline .9 & .5 & .3 & 1.0 & 2.5 & .79 & -.01 & -.16 & .68 & -.02 & -.28 \\
\hline .9 & .8 & .8 & .5 & 1.1 & .65 & -.04 & .00 & .55 & -.06 & .00 \\
\hline .9 & .8 & .8 & .5 & 2.5 & .43 & -.04 & -.44 & .17 & -.06 & -.76 \\
\hline .9 & .8 & .8 & 1.0 & 2.5 & .37 & -.03 & -.38 & .13 & -.05 & -.60 \\
\hline
\end{tabular}

Table 2

Reduced Form for Contemporaneous Expectational Structural Model

\begin{tabular}{|c|c|c|c|c|c|c|c|c|c|c|c|c|c|c|c|c|}
\hline \multicolumn{3}{|c|}{ Model } & \multicolumn{2}{|c|}{ Rule } & \multicolumn{6}{|c|}{ Output Reduced Form } & \multicolumn{6}{|c|}{ Inflation Reduced Form } \\
\hline$\mu_{r}$ & $\mu_{\pi}$ & $\mu_{y}$ & $g_{y}$ & $g_{\pi}$ & $b_{y y}$ & $b_{y i}$ & $b_{y \pi}$ & $b_{y \varepsilon}$ & $b_{y \eta}$ & $b_{y \xi}$ & $b_{\pi y}$ & $b_{\pi i}$ & $b_{\pi \pi}$ & $b_{\pi \varepsilon}$ & $b_{\pi \eta}$ & $b_{\pi \xi}$ \\
\hline 0 & 0 & 0 & .5 & 1.1 & .95 & -.10 & .10 & 1.00 & .00 & .00 & .10 & .00 & 1.00 & .00 & 1.00 & .00 \\
\hline 0 & 0 & 0 & .5 & 2.5 & .95 & -.10 & .10 & 1.00 & .00 & .00 & .10 & .00 & 1.00 & .00 & 1.00 & .00 \\
\hline 0 & 0 & 0 & 1.0 & 2.5 & .95 & -.10 & .10 & 1.00 & .00 & .00 & .10 & .00 & 1.00 & .00 & 1.00 & .00 \\
\hline .5 & .3 & .1 & .5 & 1.1 & .93 & -.05 & .11 & 1.08 & .00 & -.06 & .24 & -.01 & 1.01 & .11 & 1.43 & -.01 \\
\hline .5 & .3 & .1 & .5 & 2.5 & .90 & -.05 & .01 & 1.07 & -.13 & -.06 & .23 & -.01 & .99 & .10 & 1.40 & -.01 \\
\hline .5 & .3 & .1 & 1.0 & 2.5 & .87 & -.05 & .01 & 1.08 & -.13 & -.06 & .22 & -.00 & .99 & .10 & 1.41 & -.01 \\
\hline .9 & .5 & .3 & .5 & 1.1 & .75 & -.01 & .07 & 1.20 & -.05 & -.11 & -.12 & .00 & .07 & -.10 & 1.42 & .01 \\
\hline .9 & .5 & .3 & .5 & 2.5 & .75 & -.01 & -.06 & 1.18 & -.35 & -.11 & .44 & -.00 & .81 & .43 & 1.54 & -.04 \\
\hline .9 & .5 & .3 & 1.0 & 2.5 & .70 & -.01 & -.05 & 1.10 & -.33 & -.10 & .41 & -.00 & .83 & .38 & 1.58 & -.04 \\
\hline .9 & .8 & .8 & .5 & 1.1 & .22 & -.01 & .12 & 1.17 & .02 & -.12 & .17 & -.00 & .28 & .20 & 1.28 & -.02 \\
\hline .9 & .8 & .8 & .5 & 2.5 & .18 & -.01 & .06 & 1.09 & -.24 & -.11 & .15 & -.00 & .26 & .17 & 1.22 & -.02 \\
\hline .9 & .8 & .8 & 1.0 & 2.5 & .17 & -.01 & .06 & 1.03 & -.23 & -.10 & .15 & -.00 & .26 & .15 & 1.22 & -.02 \\
\hline
\end{tabular}


Table 3

Model Parameter Values

\begin{tabular}{|c|c|c|}
\hline Coefficient & Value & Standard error \\
\hline$\alpha_{\pi 1}$ & .67 & .13 \\
\hline$\alpha_{\pi 2}$ & -.14 & .15 \\
\hline$\alpha_{\pi 3}$ & .40 & .15 \\
\hline$\alpha_{\pi 4}$ & .07 & - \\
\hline$\alpha_{y}$ & .13 & .04 \\
\hline$\beta_{y 1}$ & 1.15 & .09 \\
\hline$\beta_{y 2}^{g 1}$ & -.27 & .09 \\
\hline$\beta_{r}$ & .09 & .03 \\
\hline$\sigma_{\varepsilon}$ & 1.012 & - \\
\hline$\sigma_{\eta}$ & .833 & - \\
\hline
\end{tabular}

Note: Obtained from Rudebusch (2002).

Table 4

Probabilities of Rejecting the Null Hypothesis of Parameter Stability for Estimated Model 0 Equations

\begin{tabular}{|c|c|c|c|c|c|c|}
\hline Policy rule & & \multirow{2}{*}{$\begin{array}{c}\text { Estimated } \\
\text { equation }\end{array}$} & \multicolumn{4}{|c|}{ Model used to generate data } \\
\hline First half & Second half & & Model 0 & Model 1 & Model 2 & Model 3 \\
\hline
\end{tabular}

Panel A. Same policy rule used in first and second halves of sample

$\begin{array}{llcllll}\mathrm{Ta} & \mathrm{Ta} & \text { output } & .050 & .044 & .044 & .048 \\ \mathrm{Ta} & \mathrm{Ta} & \text { inflation } & .046 & .039 & .033 & .041 \\ \mathrm{~Tb} & \mathrm{~Tb} & \text { output } & .050 & .051 & .047 & .052 \\ \mathrm{~Tb} & \mathrm{~Tb} & \text { inflation } & .043 & .039 & .038 & .040\end{array}$

Panel B. Different policy rules used in first and second halves of sample

\begin{tabular}{|c|c|c|c|c|c|c|}
\hline $\mathrm{Ta}$ & $\mathrm{Tb}$ & output & .047 & .061 & .091 & .060 \\
\hline $\mathrm{Ta}$ & $\mathrm{Tb}$ & inflation & .048 & .046 & .086 & .042 \\
\hline CGGa & CGGb & output & .050 & .088 & .158 & .075 \\
\hline CGGa & CGGb & inflation & .052 & .049 & .134 & .048 \\
\hline $\mathrm{EFa}$ & $\mathrm{EFb}$ & output & .048 & .076 & .158 & \\
\hline $\mathrm{EFa}$ & $\mathrm{EFb}$ & inflation & 048 & .048 & 062 & \\
\hline
\end{tabular}

Note: A given model (Model 0, 1, 2, or 3) is used to generate 240 observations using a policy rule that may differ across the first and second halves of the sample. The table entries are $p$-values - using 5 percent critical values - of the null hypothesis that the estimated (Model 0) output and inflation equations are stable. 
Table 5

Estimated Model 0 Coefficients for Various Models and Rules

\begin{tabular}{|c|c|c|c|c|c|c|c|c|c|c|}
\hline \multicolumn{2}{|c|}{ Data generation } & \multicolumn{9}{|c|}{ Average Model 0 coefficients estimated from simulated data } \\
\hline Model & Rule & $\beta_{y 1}$ & $\beta_{y 2}$ & $\beta_{r}$ & $\alpha_{\pi 1}$ & $\alpha_{\pi 2}$ & $\alpha_{\pi 3}$ & $\alpha_{\pi 4}$ & $\alpha_{y}$ & $\sum_{j=1}^{4} \alpha_{\pi j}$ \\
\hline 1 & $\mathrm{Ta}$ & $\begin{array}{l}1.12 \\
(.06)\end{array}$ & $\begin{array}{l}-.28 \\
(.06)\end{array}$ & $\begin{array}{l}.07 \\
(.03)\end{array}$ & $\begin{array}{l}.65 \\
(.06)\end{array}$ & $\begin{array}{l}-.05 \\
(.08)\end{array}$ & $\begin{array}{l}.35 \\
(.07)\end{array}$ & $\begin{array}{c}.03 \\
(.06)\end{array}$ & $\begin{array}{l}.20 \\
(.04)\end{array}$ & $\begin{array}{c}.99 \\
(.02)\end{array}$ \\
\hline 1 & $\mathrm{~Tb}$ & $\begin{array}{l}1.09 \\
(.09)\end{array}$ & $\begin{array}{l}-.27 \\
(.09)\end{array}$ & $\begin{array}{l}.11 \\
(.04)\end{array}$ & $\begin{array}{l}.64 \\
(.09)\end{array}$ & $\begin{array}{l}-.06 \\
(.11)\end{array}$ & $\begin{array}{l}.35 \\
(.11)\end{array}$ & $\begin{array}{l}.03 \\
(.09)\end{array}$ & $\begin{array}{l}.19 \\
(.06)\end{array}$ & $\begin{array}{l}.96 \\
(.05)\end{array}$ \\
\hline 1 & CGGa & $\begin{array}{l}1.12 \\
(.09)\end{array}$ & $\begin{array}{l}-.28 \\
(.09)\end{array}$ & $\begin{array}{l}.06 \\
(.11)\end{array}$ & $\begin{array}{l}.65 \\
(.09)\end{array}$ & $\begin{array}{l}-.05 \\
(.11)\end{array}$ & $\begin{array}{l}.35 \\
(.10)\end{array}$ & $\begin{array}{l}.03 \\
(.09)\end{array}$ & $\begin{array}{l}.20 \\
(.06)\end{array}$ & $\begin{array}{l}.99 \\
(.03)\end{array}$ \\
\hline 1 & CGGb & $\begin{array}{l}1.08 \\
(.09)\end{array}$ & $\begin{array}{l}-.28 \\
(.08)\end{array}$ & $\begin{array}{l}.10 \\
(.03)\end{array}$ & $\begin{array}{l}.64 \\
(.09)\end{array}$ & $\begin{array}{l}-.06 \\
(.11)\end{array}$ & $\begin{array}{l}.35 \\
(.11)\end{array}$ & $\begin{array}{l}.02 \\
(.09)\end{array}$ & $\begin{array}{l}.20 \\
(.06)\end{array}$ & $\begin{array}{l}.95 \\
(.07)\end{array}$ \\
\hline 1 & $\mathrm{EFa}$ & $\begin{array}{l}1.10 \\
(.09)\end{array}$ & $\begin{array}{l}-.29 \\
(.09)\end{array}$ & $\begin{array}{l}.09 \\
(.05)\end{array}$ & $\begin{array}{l}.65 \\
(.09)\end{array}$ & $\begin{array}{l}-.06 \\
(.11)\end{array}$ & $\begin{array}{c}.35 \\
(.10)\end{array}$ & $\begin{array}{l}.03 \\
(.09)\end{array}$ & $\begin{array}{l}.19 \\
(.06)\end{array}$ & $\begin{array}{l}.97 \\
(.04)\end{array}$ \\
\hline 1 & $\mathrm{EFb}$ & $\begin{array}{l}1.14 \\
(.09)\end{array}$ & $\begin{array}{l}-.32 \\
(.08)\end{array}$ & $\begin{array}{l}.11 \\
(.04)\end{array}$ & $\begin{array}{l}.65 \\
(.09)\end{array}$ & $\begin{array}{l}-.06 \\
(.11)\end{array}$ & $\begin{array}{l}.35 \\
(.11)\end{array}$ & $\begin{array}{c}.02 \\
(.09)\end{array}$ & $\begin{array}{l}.22 \\
(.05)\end{array}$ & $\begin{array}{l}.98 \\
(.04)\end{array}$ \\
\hline 2 & $\mathrm{Ta}$ & $\begin{array}{l}1.06 \\
(.09)\end{array}$ & $\begin{array}{l}-.31 \\
(.09)\end{array}$ & $\begin{array}{l}.03 \\
(.12)\end{array}$ & $\begin{array}{l}.60 \\
(.09)\end{array}$ & $\begin{array}{l}.00 \\
(.11)\end{array}$ & $\begin{array}{l}.29 \\
(.10)\end{array}$ & $\begin{array}{l}.01 \\
(.09)\end{array}$ & $\begin{array}{l}.27 \\
(.06)\end{array}$ & $\begin{array}{l}.89 \\
(.05)\end{array}$ \\
\hline 2 & $\mathrm{~Tb}$ & $\begin{array}{l}.98 \\
(.09)\end{array}$ & $\begin{array}{l}-.29 \\
(.09)\end{array}$ & $\begin{array}{l}.10 \\
(.06)\end{array}$ & $\begin{array}{l}.54 \\
(.09)\end{array}$ & $\begin{array}{l}-.03 \\
(.10)\end{array}$ & $\begin{array}{l}.27 \\
(.10)\end{array}$ & $\begin{array}{l}.00 \\
(.09)\end{array}$ & $\begin{array}{l}.20 \\
(.07)\end{array}$ & $\begin{array}{l}.79 \\
(.09)\end{array}$ \\
\hline 2 & CGGa & $\begin{array}{l}1.05 \\
(.09)\end{array}$ & $\begin{array}{l}-.30 \\
(.09)\end{array}$ & $\begin{array}{l}.03 \\
(.12)\end{array}$ & $\begin{array}{l}.60 \\
(.09)\end{array}$ & $\begin{array}{l}.00 \\
(.11)\end{array}$ & $\begin{array}{l}.29 \\
(.10)\end{array}$ & $\begin{array}{l}.01 \\
(.09)\end{array}$ & $\begin{array}{l}.26 \\
(.06)\end{array}$ & $\begin{array}{l}.90 \\
(.05)\end{array}$ \\
\hline 2 & CGGb & $\begin{array}{l}.96 \\
(.09)\end{array}$ & $\begin{array}{l}-.31 \\
(.09)\end{array}$ & $\begin{array}{l}.10 \\
(.05)\end{array}$ & $\begin{array}{l}.52 \\
(.09)\end{array}$ & $\begin{array}{l}-.04 \\
(.10)\end{array}$ & $\begin{array}{l}.25 \\
(.10)\end{array}$ & $\begin{array}{l}.00 \\
(.09)\end{array}$ & $\begin{array}{l}.18 \\
(.07)\end{array}$ & $\begin{array}{l}.73 \\
(.12)\end{array}$ \\
\hline 2 & $\mathrm{EFa}$ & $\begin{array}{l}.99 \\
(.09)\end{array}$ & $\begin{array}{l}-.34 \\
(.09)\end{array}$ & $\begin{array}{l}.03 \\
(.06)\end{array}$ & $\begin{array}{l}.54 \\
(.09)\end{array}$ & $\begin{array}{l}-.02 \\
(.10)\end{array}$ & $\begin{array}{l}.27 \\
(.10)\end{array}$ & $\begin{array}{c}.01 \\
(.09)\end{array}$ & $\begin{array}{l}.19 \\
(.08)\end{array}$ & $\begin{array}{l}.80 \\
(.09)\end{array}$ \\
\hline 2 & $\mathrm{EFb}$ & $\begin{array}{l}1.12 \\
(.10)\end{array}$ & $\begin{array}{l}-.39 \\
(.09)\end{array}$ & $\begin{array}{l}.05 \\
(.07)\end{array}$ & $\begin{array}{l}.52 \\
(.09)\end{array}$ & $\begin{array}{l}-.04 \\
(.10)\end{array}$ & $\begin{array}{l}.25 \\
(.10)\end{array}$ & $\begin{array}{l}-.01 \\
(.09)\end{array}$ & $\begin{array}{l}.22 \\
(.06)\end{array}$ & $\begin{array}{l}.72 \\
(.09)\end{array}$ \\
\hline 3 & $\mathrm{Ta}$ & $\begin{array}{l}.19 \\
(.09)\end{array}$ & $\begin{array}{l}-.08 \\
(.09)\end{array}$ & $\begin{array}{l}-.05 \\
(.14)\end{array}$ & $\begin{array}{l}.22 \\
(.09)\end{array}$ & $\begin{array}{l}-.02 \\
(.10)\end{array}$ & $\begin{array}{l}.11 \\
(.09)\end{array}$ & $\begin{array}{l}.00 \\
(.09)\end{array}$ & $\begin{array}{c}.03 \\
(.12)\end{array}$ & $\begin{array}{l}.32 \\
(.15)\end{array}$ \\
\hline 3 & $\mathrm{~Tb}$ & $\begin{array}{l}.19 \\
(.09)\end{array}$ & $\begin{array}{l}-.08 \\
(.09)\end{array}$ & $\begin{array}{l}.03 \\
(.09)\end{array}$ & $\begin{array}{l}.21 \\
(.10)\end{array}$ & $\begin{array}{l}-.03 \\
(.09)\end{array}$ & $\begin{array}{l}.10 \\
(.09)\end{array}$ & $\begin{array}{l}.00 \\
(.09)\end{array}$ & $\begin{array}{l}.03 \\
(.11)\end{array}$ & $\begin{array}{l}.28 \\
(.16)\end{array}$ \\
\hline 3 & CGGa & $\begin{array}{l}.19 \\
(.09)\end{array}$ & $\begin{array}{l}-.08 \\
(.09)\end{array}$ & $\begin{array}{l}-.05 \\
(.14)\end{array}$ & $\begin{array}{l}.22 \\
(.09)\end{array}$ & $\begin{array}{l}-.02 \\
(.10)\end{array}$ & $\begin{array}{l}.11 \\
(.09)\end{array}$ & $\begin{array}{c}.01 \\
(.09)\end{array}$ & $\begin{array}{l}.03 \\
(.12)\end{array}$ & $\begin{array}{l}.32 \\
(.15)\end{array}$ \\
\hline 3 & CGGb & $\begin{array}{l}.20 \\
(.09)\end{array}$ & $\begin{array}{l}-.09 \\
(.09)\end{array}$ & $\begin{array}{l}.06 \\
(.06)\end{array}$ & $\begin{array}{l}.20 \\
(.10)\end{array}$ & $\begin{array}{l}-.05 \\
(.09)\end{array}$ & $\begin{array}{l}.09 \\
(.09)\end{array}$ & $\begin{array}{l}.00 \\
(.09)\end{array}$ & $\begin{array}{l}.03 \\
(.12)\end{array}$ & $\begin{array}{l}.23 \\
(.17)\end{array}$ \\
\hline 3 & $\mathrm{EFa}$ & $\begin{array}{l}.17 \\
(.09)\end{array}$ & $\begin{array}{l}-.10 \\
(.09)\end{array}$ & $\begin{array}{l}-.08 \\
(.10)\end{array}$ & $\begin{array}{l}.20 \\
(.10)\end{array}$ & $\begin{array}{l}-.04 \\
(.10)\end{array}$ & $\begin{array}{l}.09 \\
(.09)\end{array}$ & $\begin{array}{l}.00 \\
(.09)\end{array}$ & $\begin{array}{c}.02 \\
(.12)\end{array}$ & $\begin{array}{l}.25 \\
(.16)\end{array}$ \\
\hline 3 & $\mathrm{EFb}$ & $\begin{array}{l}.22 \\
(.09)\end{array}$ & $\begin{array}{l}-.06 \\
(.10)\end{array}$ & $\begin{array}{l}-.07 \\
(.09)\end{array}$ & $\begin{array}{l}.19 \\
(.10)\end{array}$ & $\begin{array}{l}-.05 \\
(.09)\end{array}$ & $\begin{array}{l}.07 \\
(.09)\end{array}$ & $\begin{array}{l}-.02 \\
(.09)\end{array}$ & $\begin{array}{l}.03 \\
(.11)\end{array}$ & $\begin{array}{l}.19 \\
(.17)\end{array}$ \\
\hline
\end{tabular}

Note: For each row, 5000 samples of size 120 are generated for a given (expectational) model and rule. For each sample, the quasi-reduced-form inflation and output equations of Model 0 are estimated, and the mean of each parameter across the 5000 samples is reported along with its standard deviation in parentheses. The final column reports the average estimated sum of the own-lag coefficients in the inflation equation along with its standard deviation in parentheses. 


\section{Table 6}

\section{Probabilities of Rejecting the Null Hypothesis of Parameter Stability} Assuming a High Interest Rate Sensitivity $\left(\beta_{r}=.2\right)$

\begin{tabular}{|c|c|c|c|c|c|}
\hline \multicolumn{2}{|c|}{ Policy rule } & \multirow{2}{*}{$\begin{array}{c}\text { Estimated } \\
\text { equation }\end{array}$} & \multicolumn{3}{|c|}{ Model used to generate data } \\
\hline First half & Second half & & Model 0 & Model 2 & Model 3 \\
\hline
\end{tabular}

Panel A. Same policy rule used in first and second halves of sample

$\begin{array}{llcllll}\mathrm{Ta} & \mathrm{Ta} & \text { output } & .046 & .044 & .045 & .048 \\ \mathrm{Ta} & \mathrm{Ta} & \text { inflation } & .048 & .038 & .037 & .039 \\ \mathrm{~Tb} & \mathrm{~Tb} & \text { output } & .047 & .051 & .052 & .048 \\ \mathrm{~Tb} & \mathrm{~Tb} & \text { inflation } & .042 & .039 & .040 & .039\end{array}$

Panel B. Different policy rules used in first and second halves of sample

$\begin{array}{ccccccc}\mathrm{Ta} & \mathrm{Tb} & \text { output } & .059 & .087 & .147 & .078 \\ \mathrm{Ta} & \mathrm{Tb} & \text { inflation } & .050 & .052 & .066 & .043 \\ & & & & & & \\ \mathrm{CGGa} & \mathrm{CGGb} & \text { output } & .064 & .177 & .224 & .117 \\ \mathrm{CGGa} & \mathrm{CGGb} & \text { inflation } & .060 & .050 & .088 & .052 \\ & & & & & & \\ \mathrm{EFa} & \mathrm{EFb} & \text { output } & .047 & .066 & .454 & .124 \\ \mathrm{EFa} & \mathrm{EFb} & \text { inflation } & .045 & .073 & .079 & .050\end{array}$

\footnotetext{
Note: A given model (Model 0, 1, 2, or 3) is used to generate 240 observations of data using a policy rule that may differ across the first and second halves of the sample. The table entries are $p$-values - using 5 percent critical values - of the null hypothesis that the estimated (Model 0) output and inflation equations are stable.
} 


\section{References}

[1] Anderson, Gary S., and George Moore (1985), "A Linear Algebraic Procedure for Solving Linear Perfect Foresight Models," Economics Letters 17, 247-52.

[2] Bernanke, Ben and Ilian Mihov (1998), "Measuring Monetary Policy," Quarterly Journal of Economics 113, 869-902.

[3] Boivin, Jean, and Marc Giannoni (2002), "Assessing Changes in the Monetary Transmission Mechanism: A VAR Approach," Economic Policy Review, Federal Reserve Bank of New York, no. 1, 97-111.

[4] Christiano, Lawrence, Martin Eichenbaum, and Charles Evans (2001), "Nominal Rigidities and the Dynamic Effects of a Shock to Monetary Policy," NBER working paper 8403.

[5] Clark, Peter, Douglas Laxton, and David Rose (1996). "Asymmetry in the U.S. OutputInflation Nexus," IMF Staff Papers 43, 216-251.

[6] Clarida, Richard, Jordi Gali, and Mark Gertler (1999), "The Science of Monetary Policy: A New Keynesian Perspective," Journal of Economic Literature 37, 1661-1707.

[7] Clarida, Richard, Jordi Gali, and Mark Gertler (2000), "Monetary Policy Rules and Macroeconomic Stability: Evidence and Some Theory," Quarterly Journal of Economics 115, 147180 .

[8] Cogley, Timothy, and James Nason (1995), "Output Dynamics in Real-Business-Cycle Models," American Economic Review 85, 492-511.

[9] Dennis, Richard (2001), "The Policy Preferences of the U.S. Federal Reserve," Federal Reserve Bank of San Francisco, Working Paper 01-08.

[10] Estrella, Arturo, and Jeffrey C. Fuhrer (1998), "Dynamic Inconsistencies: Counterfactual Implications of a Class of Rational Expectations Models," Working Paper No. 98-5, Federal Reserve Bank of Boston.

[11] Estrella, Arturo and Jeffrey C. Fuhrer (2000), "Are 'Deep' Parameters Stable? The Lucas Critique as an Empirical Hypothesis," manuscript, Federal Reserve Bank of Boston.

[12] Fagan, Gabriel, Jerome Henry, and Ricardo Mestre (2001), "An Area-Wide Model (AWM) for the Euro Area," Working Paper No. 42, European Central Bank.

[13] Fuhrer, Jeffrey C. (1997), "The (Un)Importance of Forward-Looking Behavior in Price Specifications," Journal of Money, Credit, and Banking (August), 338-350.

[14] Fuhrer, Jeffrey C. (2000), "Habit Formation in Consumption and Its Implications for Monetary-Policy Models," American Economic Review 90, 367-90.

[15] Fuhrer, Jeffery C., and George R. Moore (1995), "Monetary Policy Trade-Offs and the Correlation Between Nominal Interest Rates and Real Output," American Economic Review 85, 219-239.

[16] Judd, John, and Glenn Rudebusch (1998), "Taylor's Rule and the Fed: 1970-1997," Economic Review, Federal Reserve Bank of San Francisco, no. 3, 3-16. 
[17] Lansing, Kevin, and Bharat Trehan (2001), "Forward-Looking Behavior and the Optimality of the Taylor Rule," Federal Reserve Bank of San Francisco Working Paper 01-03.

[18] Laubach, Thomas, and John C. Williams (2001), "Measuring the Natural Rate of Interest," Federal Reserve Board, manuscript.

[19] Leeper, Eric, and Tao Zha (2001), "Empirical Analysis of Policy Interventions," manuscript, Federal Reserve Bank of Atlanta.

[20] Lindé, Jesper (2001) "Testing for the Lucas Critique: A Quantitative Investigation," American Economic Review 91, 986-1005.

[21] Lucas, Robert E. (1976), "Econometric Policy Evaluation: A Critique," Carnegie-Rochester Conference Series on Public Policy 1, 19-46.

[22] Lucas, Robert E., and Thomas Sargent (1981), "After Keynesian Macroeconomics," in Rational Expectations and Econometric Practice (University of Minnesota Press, Minneapolis), 295-319.

[23] Mankiw, Greg, and Ricardo Reis (2001), "Sticky Information: A Model of Monetary Nonneutrality and Structural Slumps," NBER working paper 8614.

[24] McCallum, Bennett T., and Edward Nelson (1999), "Nominal Income Targeting in an Open-Economy Optimizing Model," Journal of Monetary Economics 43, 553-578.

[25] Oliner, Stephen, Glenn Rudebusch, and Daniel Sichel (1996), "The Lucas Critique Revisited: Assessing the Stability of Empirical Euler Equations for Investment," Journal of Econometrics 70, 291-316.

[26] Onatski, Alexei, and James H. Stock (2002), "Robust Monetary Policy Under Model Uncertainty in a Small Model of the U.S. Economy," Macroeconomic Dynamics 6, 85-110.

[27] Roberts, John M. (1995), "New Keynesian Economics and the Phillips Curve," Journal of Money, Credit, and Banking 27 (November), 975-984.

[28] Rotemberg, Julio, and Michael Woodford (1999), "Interest Rate Rules in an Estimated Sticky Price Model," in Monetary Policy Rules, edited by John B. Taylor, Chicago: Chicago University Press, 57-119.

[29] Rudebusch, Glenn D. (1998), "Do Measures of Monetary Policy in a VAR Make Sense?" International Economic Review 39, 907-931.

[30] Rudebusch, Glenn D. (2001a), "Is the Fed Too Timid? Monetary Policy in an Uncertain World," Review of Economics and Statistics 83, 203-217.

[31] Rudebusch, Glenn D. (2001b), "Term Structure Evidence on Interest Rate Smoothing and Monetary policy Inertia," manuscript, Federal Reserve Bank of San Francisco, forthcoming in Journal of Monetary Economics.

[32] Rudebusch, Glenn D. (2002), "Assessing Nominal Income Rules for Monetary Policy with Model and Data Uncertainty," Economic Journal 112 (April), 1-31. 
[33] Rudebusch, Glenn D., and Lars E.O. Svensson (1999), "Policy Rules for Inflation Targeting," in Monetary Policy Rules, edited by John B. Taylor, Chicago: Chicago University Press, 203-246.

[34] Rudebusch, Glenn D., and Lars E.O. Svensson (2002), "Eurosystem Monetary Targeting: Lessons from U.S. Data.", European Economic Review 46, 417-442.

[35] Sargent, Thomas J., (1999), The Conquest of American Inflation, Princeton, NJ: Princeton University Press.

[36] Sims, Christopher (1982), "Policy Analysis with Econometric Models," Brookings Papers on Economic Activity, Vol. 1, 107-152.

[37] Smets, Frank (1999), "Output Gap Uncertainty: Does It Matter for the Taylor Rule?" in Monetary Policy Under Uncertainty, edited by Benjamin Hunt and Adrian Orr, Wellington, New Zealand: Reserve Bank of New Zealand, 10-29.

[38] Svensson, Lars E. O. (1997), "Inflation Forecast Targeting: Implementing and Monitoring Inflation Targets," European Economic Review 41, 1111-1146.

[39] Svensson, Lars E.O. (1999a), "Inflation Targeting: Some Extensions," Scandinavian Journal of Economics 101, 337-361.

[40] Svensson, Lars E.O. (1999b), "Inflation Targeting as a Monetary Policy Rule," Journal of Monetary Economics 43, 607-654.

[41] Swaine, Daniel (2001), "Are Taste and Technology Parameters Stable?: A Test of 'Deep' Parameter Stability in Real Business Cycle Models of the U.S. Economy," manuscript, Federal Reserve Bank of Boston.

[42] Taylor, John B. (1984), "Recent Changes in Macro Policy and Its Effects: Some Time-Series Evidence," American Economic Review Papers and Proceedings 74, 206-210.

[43] Taylor, John B. (1989), "Monetary Policy and the Stability of Macroeconomic Relationships," Journal of Applied Econometrics 4, S161-S178.

[44] Taylor, John B. (1993), "Discretion versus Policy Rules in Practice," Carnegie-Rochester Conference Series on Public Policy 39, 195-214.

[45] Taylor, John B. (1999), "A Historical Analysis of Monetary Policy Rules," in Monetary Policy Rules, edited by John B. Taylor, Chicago: Chicago University Press, 319-341.

[46] Walsh, Carl E. (1984), "Interest Rate Volatility and Monetary Policy," Journal of Money, Credit, and Banking 16, 133-150.

[47] Walsh, Carl E. (1998), Monetary Theory and Policy, Cambridge MA: MIT Press. 
Figure 1. Impulse Responses for Six Versions of Model 0 Obtained from Model 1 with Six Policy Rules
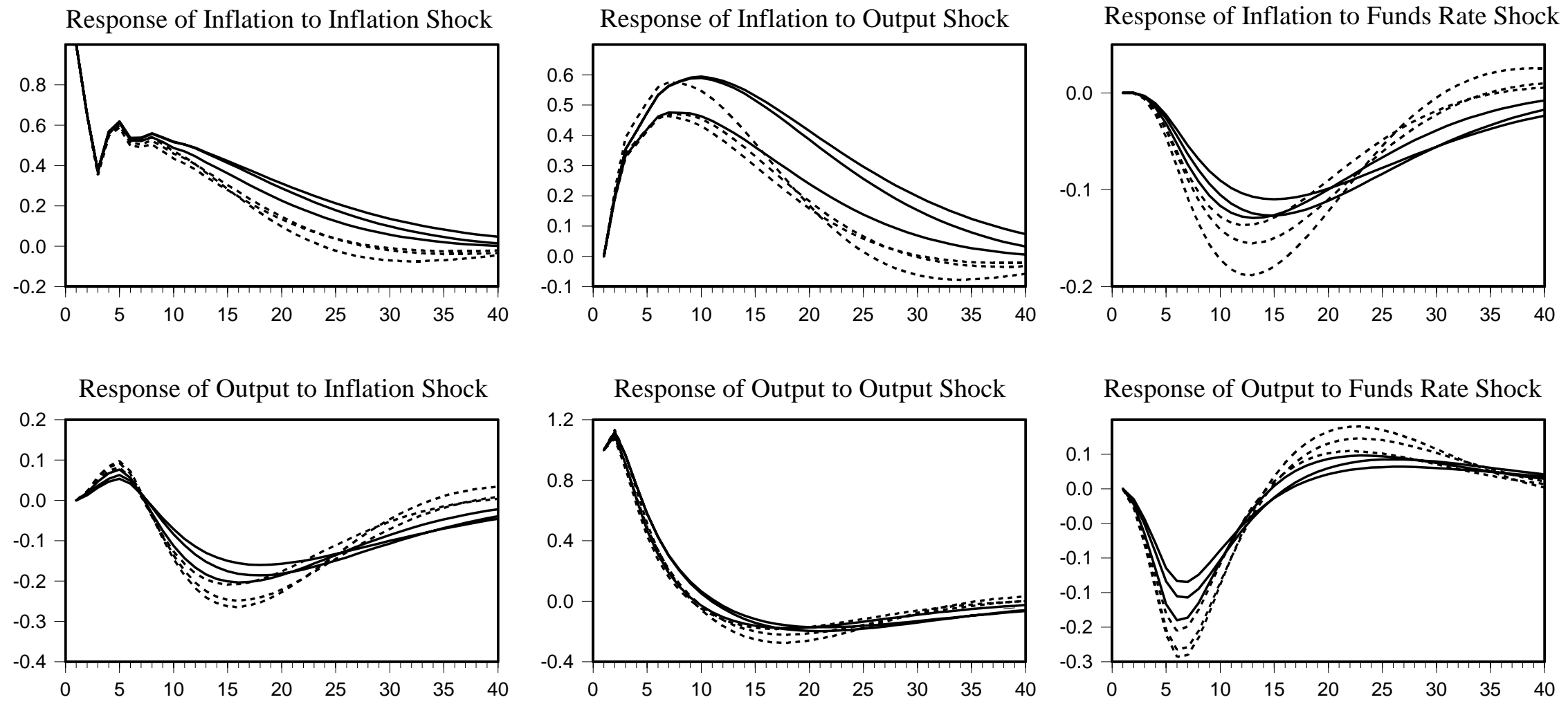

Response of Output to Funds Rate Shock

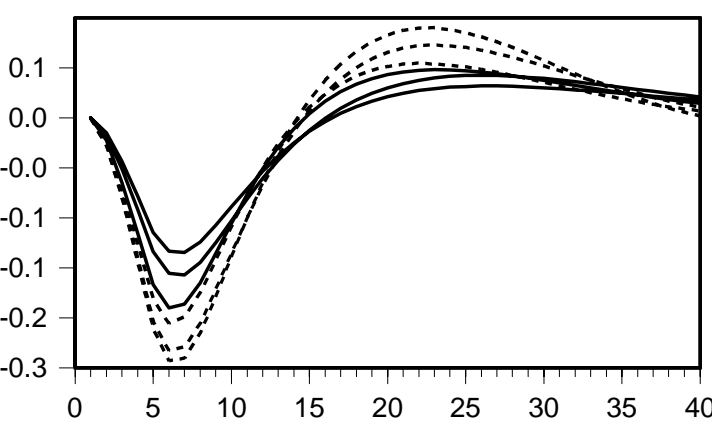

Response of Funds Rate to Inflation Shock

Response of Funds Rate to Output Shock

Response of Funds Rate to Funds Rate Shock
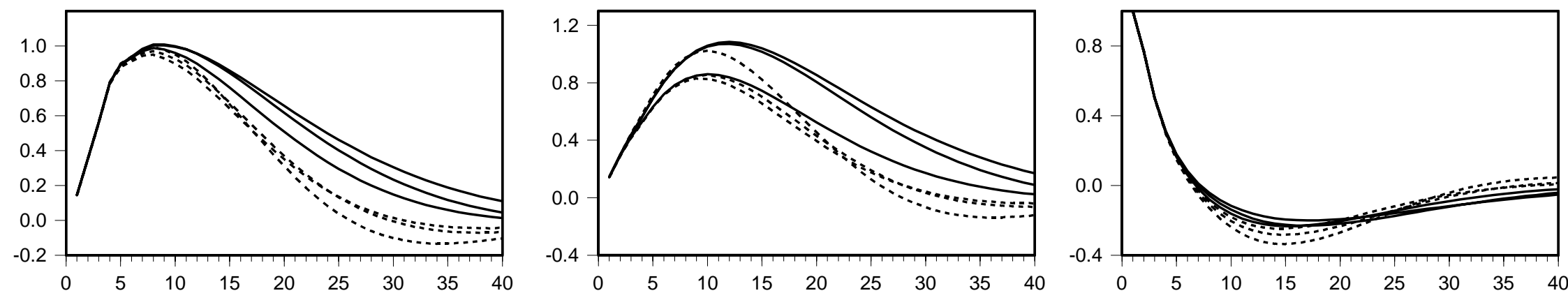
Figure 2. Impulse Responses for Six Versions of Model 0 Obtained from Model 2 with Six Policy Rules
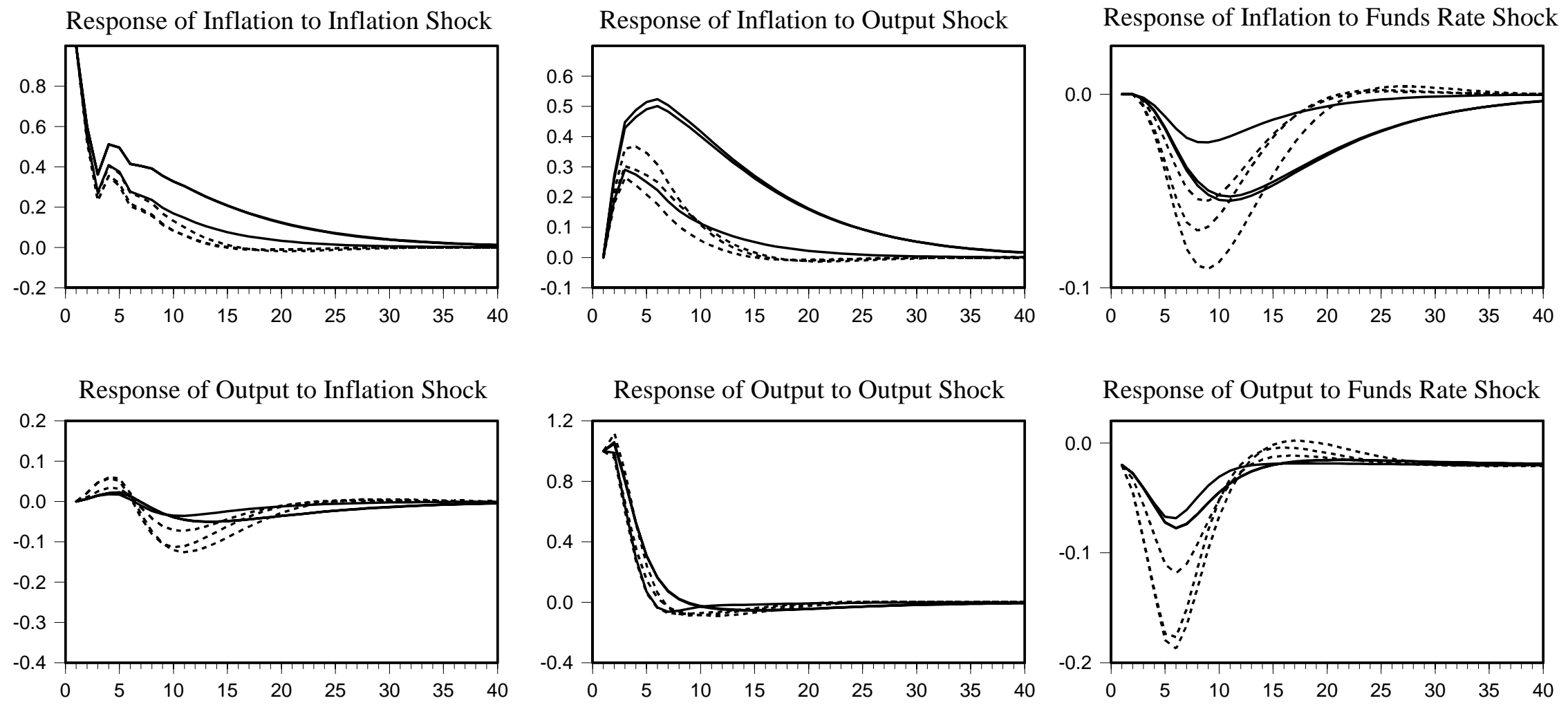

Response of Output to Funds Rate Shock

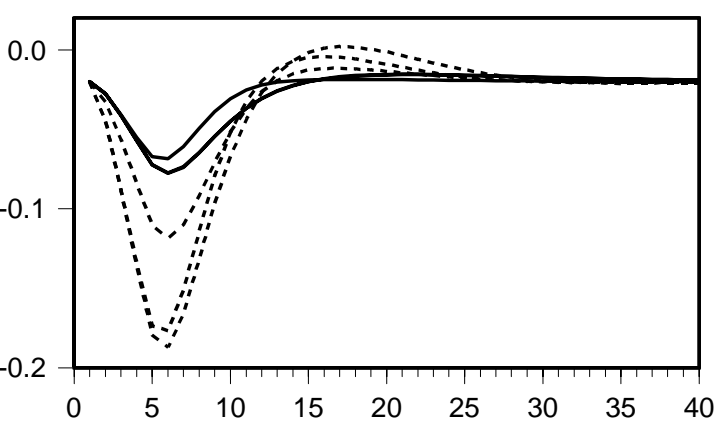

Response of Funds Rate to Inflation Shock

Response of Funds Rate to Output Shock

Response of Funds Rate to Funds Rate Shock
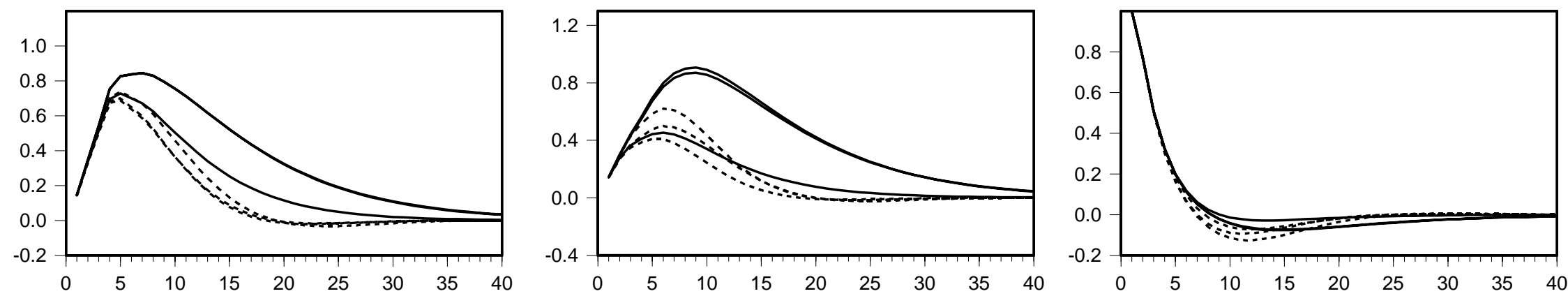
Figure 3. Impulse Responses for Six Versions of Model 0 Obtained from Model 3 with Six Policy Rules
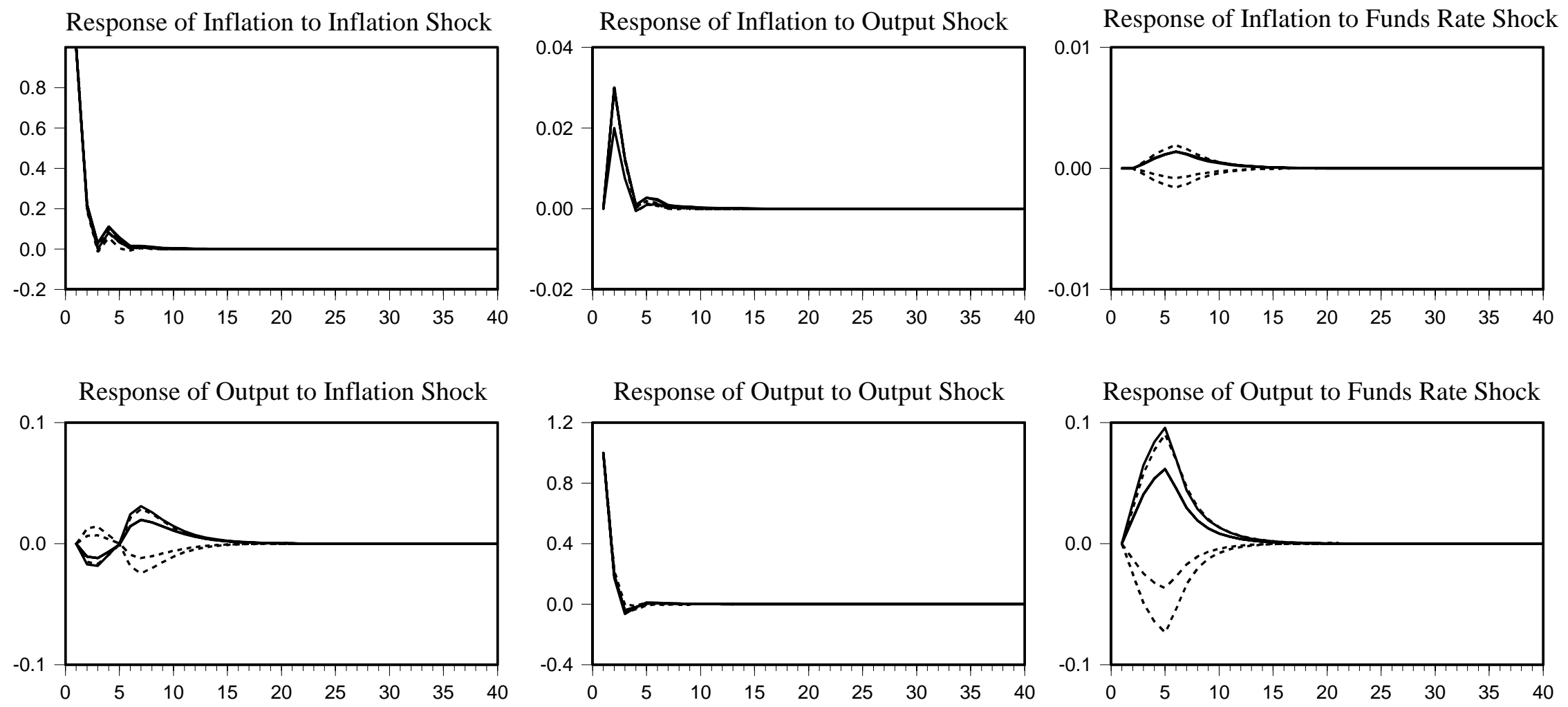

Response of Output to Funds Rate Shock

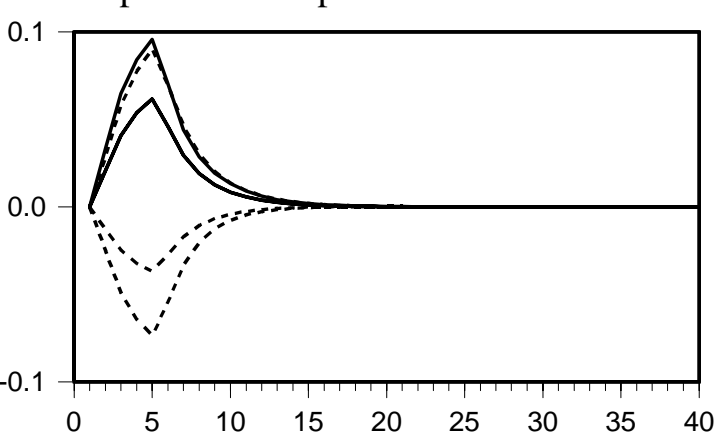

Response of Funds Rate to Inflation Shock

Response of Funds Rate to Output Shock
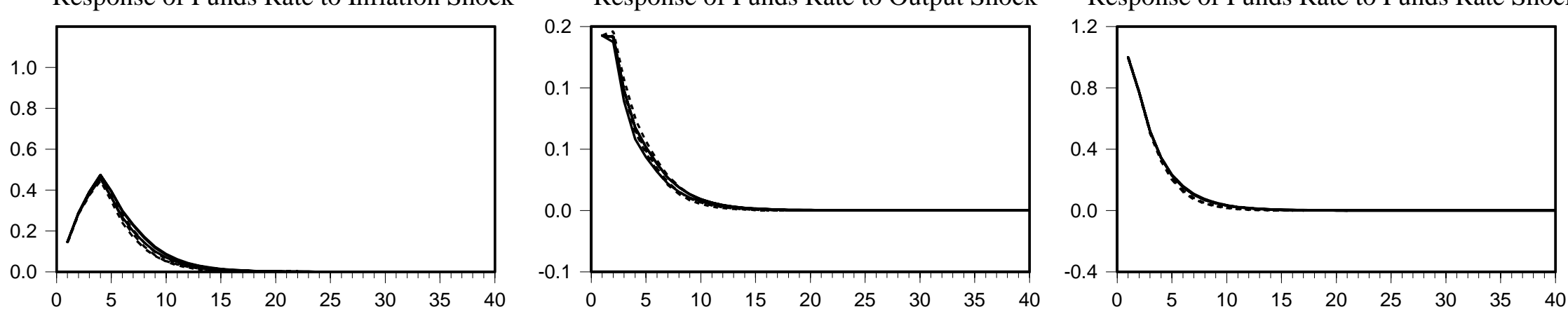